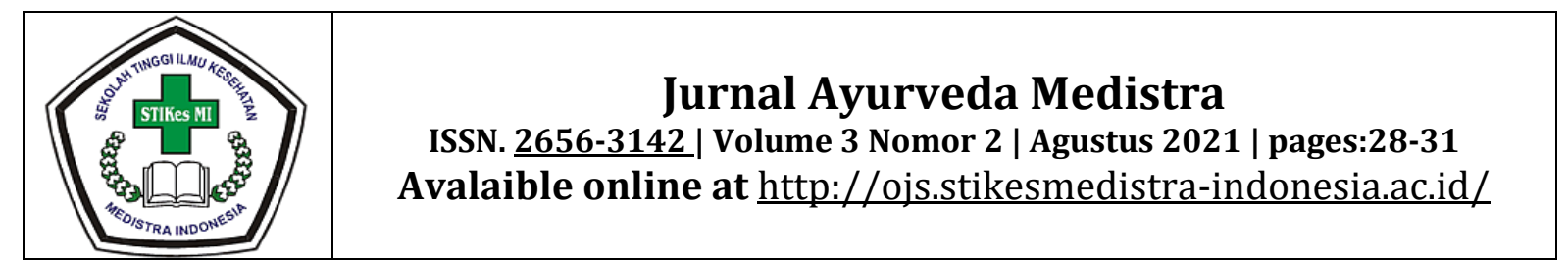

\title{
HUBUNGAN SENAM HAMIL DENGAN KEJADIAN PERSALINAN LAMA KALA I PADA IBU BERSALIN DI KLINIK PRATAMA RATNA KOMALA BEKASI
}

\author{
Puri Kresna Wati, Dewi Rostianingsih, Enika \\ Program Studi Kebidanan (D3 ) STIKes Medistra Indonesia, purri409@gmail.com , 0811-1949-040
}

\begin{abstract}
Abstrak
Kala I memanjang adalah persalinan yang fase latennya berlangsung lebih dari 8 jam dan pada fase aktif laju pembukaannya tidak adekuat atau bervariasi, kurang dari $1 \mathrm{~cm}$ setiap jam selama sekurang-kurangnya 2 jam setelah kemajuan persalinan. Senam hamil adalah program kebugaran yang diperuntukkan bagi ibu hamilLatihan-latihan pada senam hamil dirancang khusus untuk menyehatkan dan membugarkan ibu hamil, mengurangi keluhan yang timbul selama kehamilan, serta mempersiapkan fisik dan psikis ibu dalam menghadapi persalinan. Penelitian ini bertujuan untuk mengetahui hubungan antara senam hamil dengan kejadian persalinan lama kala I pada ibu bersalin di Klinik Pratama Ratna Komala Bekasi Tahun 2019. Penelitian ini merupakan jenis penelitian kuantitatif dengan menggunakan desain penelitian cross sectional. Hasil penelitian menunjukan bahwa sebagian besar responden yang persalinannya tidak lama yakni berjumlah $22(66,7 \%)$ responden dibandingkan dengan responden yang persalinannya lama berjumlah 11 (33.3\%) responden. Terdapat hubungan senam hamil dengan kejadin persalinan lama kala 1 pada ibu bersalin di Klinik Pratama Ratna Komala Bekasi Tahun 2019. Peneliti menyarankan senam hamil hendaknya dilakukan pada ibu hamil dengan usia kehamilan trimester III sekitar 28-30 minggu kehamilan dengan frekuensi yang teratur yaitu 3 kali dalam seminggu, dan melakukan gerakan secara benar sesuai dengan instruksi yang sudah diberikan.
\end{abstract}

Kata kunci : ibu hamil, partus lama, kala 1 memanjang, senam ibu hamil

\begin{abstract}
The prolonged first stage is labor in which the latent phase lasts more than 8 hours and in the active phase the rate of dilatation is inadequate or variable, less than $1 \mathrm{~cm}$ every hour for at least 2 hours after the progress of labor. Pregnancy exercise is a fitness program intended for pregnant women. Exercises in pregnancy exercise are specifically designed to make pregnant women healthy and fit, reduce complaints that arise during pregnancy, and prepare physically and psychologically for mothers to face childbirth. This study aims to determine the relationship between pregnancy exercise and the incidence of prolonged labor in the first stage of childbirth at the Ratna Komala Primary Clinic Bekasi in 2019. This study is a quantitative type of research using a cross sectional research design. The results showed that most of the respondents whose labor was not long were $22(66.7 \%)$ respondents compared to $11(33.3 \%)$ respondents whose labor was long. There is a relationship between pregnancy exercise and the incidence of prolonged labor in the 1st stage of maternity at the Pratama Ratna Komala Clinic, Bekasi in 2019. Researchers suggest that pregnancy exercise should be performed on pregnant women with the third trimester of gestation around 28-30 weeks of gestation with a regular frequency of 3 times per week. a week, and perform the movements correctly according to the instructions that have been given.
\end{abstract}

Keywords: pregnant women, prolonged labor, prolonged 1st stage, exercise for pregnant women 


\section{PENDAHULUAN}

Senam hamil adalah program kebugaran yang diperuntukkan bagi ibu hamil. Oleh karena itu, senam hamil memiliki prinsip-prinsip gerakan khusus yang disesuaikan dengan kondisi ibu hamil. Latihan-latihan pada senam hamil dirancang khusus untuk menyehatkan dan membugarkan ibu hamil, mengurangi keluhan yang timbul selama kehamilan, serta mempersiapkan fisik dan psikis ibu dalam menghadapi persalinan. (Farida, 2015).

Beberapa keuntungan senam hamil terhadap kehamilan adanya penurunan kelainan denyut jantung, tali pusat dan mekonium, penurunan penggunaan tenaga, berkurangnya rasa sakit, serta memperbaiki skor Apgar dan psikomotor janin. Senam hamil dapat menurunkan kejadian persalinan lama sebesar 5,5 kali dibandingkan pada ibu yang tidak mengikuti senam hamil. (Yuniastari, 2014)

Menurut Varney dkk, 2007 Hubungan senam hamil dengan persalinan akan menguntungkan baik fisik maupun mental, keuntungan latihan fisik adalah untuk meningkatkan dan memperbaiki sistem peredaran darah, khususnya ke otot-otot sehingga meningkatkan kekuatan dari tonus otot serta meningkatkan sirkulasi darah ke uteroplasenta, sedangkan studi yang dilakukan pada tahun 2000 menyebutkan bahwa ibu yang tidak mengikuti senam hamil memiliki risiko 4,5 kali lebih besar untuk melahirkan dengan sectio caesar dibandingkan yang mengikuti senam hamil. (Wijayanti, 2015).

Waktu Pelaksanaan Senam Hamil dianjurkan dilakukan saat kehamilan memasuki trisemester ketiga, yaitu sekitar usia 28-30 minggu kehamilan. Selain untuk menjaga kebugaran, senam hamil juga diperlukan untuk meningkatkan kesiapan fisik dan mental calon ibu selama proses persalinan.(Farida, 2015).

Partus lama merupakan penyebab kesakitan dan kematian maternal dan perinatal terutama kala I memanjang. Kala I memanjang adalah persalinan yang fase latennya berlangsung lebih dari 8 jam dan pada fase aktif laju pembukaannya tidak adekuat atau bervariasi, kurang dari $1 \mathrm{~cm}$ setiap jam selama sekurang-kurangnya 2 jam setelah kemajuan persalinan, kurang dari 1,2 cm per jam pada primigravida dan kurang dari $1,5 \mathrm{~cm}$ per jam pada multipara, lebih dari 12 jam sejak pembukaan $4 \mathrm{~cm}$ sampai pembukaan lengkap (rata-rata 0,5 $\mathrm{cm}$ per jam). Insiden ini terjadi pada 5\% persalinan dan pada primigravida insidennya dua kali lipat lebih besar dari pada.(Lestari, 2017).

Berdasarkan data dari Klinik Pratama Ratna Komala kejadian persalinan lama kala 1 pada periode bulan Juli 2018 sebanyak 50 orang ibu bersalin, dan 33 orang diantaranya mengalami dan tidak mengalami persalinan lama kala 1 dimungkinkan karena pada saat hamil ibu melakukan atau tidak melakukan senam hamil.

Berdasarkan penelitian tersebut maka peneliti memandang perlu untuk melakukan penelitian dengan judul "Hubungan Senam Hamil Dengan Kejadian Persalinan Lama Kala I Pada Ibu Bersalin Di Klinik Pratama Ratna Komala Bekasi Tahun 2019"

\section{METODE}

Penelitian ini merupakan jenis penelitian kuantitatif dengan menggunakan desain penelitian cross sectional, untuk melihat hubungan antara variabel independent dengan variabel dependent, dengan tujuan mengetahui hubungan senam hamil dengan kejadian persalinan lama kala I pada ibu bersalin di Klinik Pratama Ratna Komala

Bekasi Tahun 2018. Populasi yang digunakan dalam penelitian ini adalah seluruh ibu bersalin di Klinik Pratama

Ratna Komala Bekasi pada bulan Desember 2019 sebanyak 50 orang. Sampel dalam penelitian ini adalah ibu bersalin di Klinik Pratama Ratna Komala Bekasi Tahun 2019 yang berjumlah 33 orang. Metode pengambilan sample pada penelitian ini menggunakan metode total sampling. 
HASIL

Penelitian ini dilakukan di Klinik Pratama Ratna Komala Bekasi pada bulan Desember 2019. Pada penelitian ini dilibatkan 33 responden ibu bersalin yang melakukan atau tidak melakukan senam hamil dan ibu bersalin yang mengalami persalinan lama atau tidak lama. Distribusi senam hamil.

Tabel 1

Distribusi responden berdasarkan senam hamil di Klinik Pratama Ratna Komala Bekasi Tahun 2019

\begin{tabular}{ccc}
\hline Senam Hamil & ımlah & $\%$ \\
\hline Dilakukan & 19 & 57.6 \\
ridak Dilakukan & 14 & 42.4 \\
Total & 33 & 00.0 \\
\hline
\end{tabular}

Sumber : Data Sekunder 2019

Berdasarkan data pada tabel dapat di lihat bahwa dari 33 responden lebih banyak responden yang melakukan senam hamil berjumlah $19(57,6 \%)$ responden dibandingkan dengan responden yang tidak melakukan senam hamil berjumlah 14 $(42,4 \%)$ responden.

Tabel 2

Distribusi responden berdasarkan persalinan lama kala 1 pada ibu bersalin di Klinik Pratama Ratna Komala Bekasi

\begin{tabular}{lll}
\hline Persalinan Lama Kala 1 & Jumlah & $\%$ \\
\hline Lama & 11 & 33.3 \\
Tidak Lama & 22 & 66.7 \\
Total & 33 & 100.0 \\
\hline
\end{tabular}

Sumber Data Sekunder 2019

Table 3

Analisis Hubungan Senam Hamil Dengan Kejadian Persalinan Lama Kala 1 Pada Ibu Bersalin Di Klinik Pratama Ratna Komala Bekasi Tahun 2019

\begin{tabular}{|c|c|c|c|c|c|c|c|}
\hline \multirow{3}{*}{ Variabel } & \multicolumn{6}{|c|}{ Persalinan Lama Kala 1} & \multirow{3}{*}{$p$} \\
\hline & \multicolumn{2}{|c|}{$\begin{array}{l}\text { Lam } \\
\text { a }\end{array}$} & \multicolumn{2}{|c|}{$\begin{array}{l}\text { Tidak } \\
\text { Lama }\end{array}$} & \multicolumn{2}{|c|}{$\begin{array}{l}\text { Tota } \\
1\end{array}$} & \\
\hline & $\mathrm{N}$ & $\%$ & $\mathrm{~N}$ & $\%$ & $\mathrm{~N}$ & $\%$ & \\
\hline $\begin{array}{l}\text { Senam } \\
\text { Hamil }\end{array}$ & & & & & & & \\
\hline Dilakukan & 2 & 10.5 & 17 & 89.5 & 19 & 100 & 0.002 \\
\hline $\begin{array}{l}\text { Tidak } \\
\text { Dilakukan }\end{array}$ & 9 & 64.2 & 5 & 35.7 & 14 & 100 & \\
\hline
\end{tabular}

Sumber: Data Sekunder 2019
Dari tabel 3 dapat dilihat bahwa dari $19 \mathrm{ibu}$ hamil yang melakukan senam hamil 17 responden $(89.5 \%)$ mengalami persalinan tidak lama dengan kategori lama $<18$ jam. Sedangkan dari 14 ibu hamil yang tidak melakukan senam hamil 9 responden (64.2 $\%)$ mengalami persalinan lama dengan kategori lama $>18$ jam. Hasil uji statistic diperoleh nilai $\mathrm{p}=0,002(<0,05)$ artinya bahwa ada hubungan senam hamil dengan kejadian persalinan lama kala 1 di Klinik Pratama Ratna Komala Bekasi tahun 2019.

\section{PEMBAHASAN}

Senam hamil merupakan salah satu kegiatan dalam pelayanan selama kehamilan atau prenatal care yang bertujuan untuk mempersiapkan dan melatih otot sehingga dapat dimanfaatkan secara optimal dalam persalinan normal. Bila dicermati lebih lanjut, sebenarnya dalam gerakan senam hamil terkandung efek relaksasi yang bermanfaat menstabilkan kecemasan dan mengurangi rasa takut dengan cara relaksasi fisik dan mental, serta mendapatkan informasi yang mempersiapkan mereka untuk mengalami apa yang akan terjadi selama persalinan dan kelahiran. Senam hamil biasanya dimulai saat kehamilan memasuki trimester ketiga, yaitu sekitar 28-30 minggu kehamilan. Hamilton (2004) menjelaskan bahwa senam hamil akan memberikan suatu produk kehamilan atau outcome persalinan yang lebih baik, dibandingkan pada ibu-ibu hamil yang tidak melakukan senam hamil selama kehamilan. Senam hamil dapat mengurangi stress dalam menjelang kelahiran, mengurangi nyeri saat proses persalinan,bayi yang dilahirkan memiliki berat badan yang normal dan dapat mengurangi resiko terjadinya preeklamsi.(Amalina, 2015). Hasil penelitian menunjukan bahwa dari 33 responden mayoritas responden yang melakukan senam hamil berjumlah 19 $(57,6 \%)$ responden dibandingkan dengan responden yang tidak melakukan senam 
hamil berjumlah 14 (42,4\%) responden. Partus lama merupakan penyebab kesakitan dan kematian maternal dan perinatal terutama kala I memanjang. Kala I memanjang adalah persalinan yang fase latennya berlangsung lebih dari 8 jam dan pada fase aktif laju pembukaannya tidak adekuat atau bervariasi, kurang dari $1 \mathrm{~cm}$ setiap jam selama sekurang-kurangnya 2 jam setelah kemajuan persalinan, kurang dari $1,2 \mathrm{~cm}$ per jam pada primigravida dan kurang dari $1,5 \mathrm{~cm}$ per jam pada multipara, lebih dari 12 jam sejak pembukaan $4 \mathrm{~cm}$ sampai pembukaan lengkap (rata-rata 0,5 $\mathrm{cm}$ per jam). Insiden ini terjadi pada 5\% persalinan dan pada primigravida insidennya dua kali lipat lebih besar dari pada multigravida. (Lestari, 2017). Hasil penelitian menunjukan bahwa sebagian besar responden yang persalinannya tidak lama yakni berjumlah $22 \quad(66,7 \%)$ responden dibandingkan dengan responden yang persalinannya lama berjumlah 11 $(33.3 \%)$ responden. Hubungan senam hamil dengan persalinan akan menguntungkan baik fisik maupun mental, keuntungan latihan fisik adalah untuk meningkatkan dan memperbaiki sistem peredaran darah, khususnya ke otot-otot sehingga meningkatkan kekuatan dari tonus otot serta meningkatkan sirkulasi darah ke uteroplasenta, sedangkan studi yang dilakukan pada tahun 2000 menyebutkan bahwa ibu yang tidak mengikuti senam hamil memiliki risiko 4,5 kali lebih besar untuk melahirkan dengan sectio caesar dibandingkan yang mengikuti senam hamil. (Wijayanti, 2015). Upaya yang dapat dilakukan ibu hamil agar persalinan berjalan normal dengan melakukan senam hamil. Senam hamil dapat membantu persalinan dengan memberikan efek positif terhadap pembukaan serviks dan aktivitas uterus yang terkoordinasi saat persalinan. Latihan-latihan yang dilakukan pada senam hamil bertujuan agar ibu hamil memperoleh kekuatan dan tonus otot yang baik, tekhnik pernafasan yang baik pada saat proses persalinan. (Elvine, 2017). Hasil penelitian ini sejalan dengan penelitian yang dilakukan oleh Atika Nur Amalina (2015) yang berjudul hubungan antara rutinitas senam hamil dengan waktu persalinan pervaginam pada primigravida di Rumah Sakit Panti Wilasa Semarang dengan nilai $p$ value $=0,003$ menunjukan ada hubungan antara rutinitas senam hamil dengan waktu persalinan pervaginam pada primigravida di Rumah Sakit Panti Wilasa Semarang Tahun 2015.

\section{Daftar Pustaka}

Amalina, A. N. (2015). Hubungan Rutinitas Senam Hamil Dengan Waktu Persalinan Pervaginam Pada Primigravida Di Rumah Sakit Panti Wilasa Semarang.

Farida, S. (2015). Senam Hamil Sebagai Upaya Untuk Memperlancar Proses Persalinan Di Rumah Sakit Kasih Ibu Surakarta, 5(1), 35-41.

Lestari, Y. (2017). Penerapan Upright Position Terhadap Lama Kala I Fase Aktif Pada Ibu Bersalin Primipara Di Bpm Puji Andriyani P, Amd. Keb Kutowinangun.

Marwiyah, N. (2017). Efektifitas Senam Hamil Terhadap Tingkat Kecemasan Ibu Hamil Trimester 2 Dan 3 Di Desa Margalahayu Wilayah Kerja Puskesmas Kasemen, XII(12), 34-40.

Soviyati, E. (2016). Faktor-Faktor Yang Berhubungan Dengan Lama Persalinan Di Rsud ' 45 Kuningan Jawa Barat Tahun 2015, 2(1).

Tandiono, E. T. (2017). Hubungan Senam Hamil Dengan Lama Proses Persalinan Kala I \& Ii Pada Ibu Hamil Primigravida Di Rsia Sakina Idaman Yogyakarta.

Wijayanti, W. (2015). Faktor-Faktor Yang Mempengaruhi Terjadinya Persalinan 
Lama Di Rspad Gatot Soebroto, 7(September), 154-164.

Yuniastari, A. D. (2014). Analisis FaktorFaktor Yang Berhubungan Dengan Pelaksanaan Senam Hamil Di Wilayah Puskesmas Purwokerto Barat Tahun 2013, 2, 283-291.

Hasmi. 2016. Metode Penelitian Kesehatan. Jayapura : In Media

Sari, Eka Puspita dan Rimandini, Kurnia Dwi, 2016. Asuhan Kebidanan Persalinan, Jakarta : TIM

Jamaan, Taufik, 2013. Panduan Praktis Kehamilan Sehat, Jakarta: onblosscreative

Karlina, Novvi dkk, 2016. Asuhan Kebidanan Kegawatdaruratan Maternal dan Neonatal, Bogor : In Media 